\title{
Comparison of Soft Computing Techniques applied in High Frequency Aircraft System
}

\author{
Saifullah Khalid \\ IET, Lucknow, UP, India \\ e-mail: saifullahkhalid@outlook.com
}

\begin{abstract}
Sinusoidal Current Control strategy for extracting reference currents for shunt active power filters have been optimized using Fuzzy Logic control and Adaptive Tabu search Algorithm and their performances have been compared. The acute analysis of Comparison of the compensation capability based on THD and speedwell be done, and recommendations will be given for the choice of technique to be used. The simulated results using MATLAB model are shown, and they will undoubtedly prove the importance of the proposed control technique of aircraft shunt APF.
\end{abstract}

Keywords: Aircraft electrical system, Shunt Active Filter (APF), Sinusoidal Current Control strategy, fuzzy logic, Adaptive Tabu search algorithm

\section{Introduction}

More advanced aircraft power systems [1]-[3] have been needed due to increased use of electrical power on behalf of other alternate sources of energy. The subsystems like flight control, flight surface actuators, passenger entertainment, are driven by electric power, which flowingly increased the demand for creating aircraft power system more intelligent and advanced. These subsystems have extensive increased electrical loads i.e. power electronic devices, increased feeding of electric power, additional demand for power, and above to all of that great stability problems.

In peculiarity to standard supply system, the source frequency is of $50 \mathrm{~Hz}$, whereas, aircraft AC power system works on the source frequency of $400 \mathrm{~Hz}$ [1]-[3]. Aircraft power utility works on source voltage of $115 / 200 \mathrm{~V}$. The loads applicable to the plane a system differs from the loads used in $50 \mathrm{~Hz}$ system [1]. When we deliberate the generation portion; aircraft power utility will remain $A C$ driven from the engine for the plane primary power. Novel fuel cell technology can be used to produce a DC output for ground power, and its silence process would match up to suitably with the Auxiliary Power Unit (APU). Though when considering the dissemination of primary power, whether AC or DC; each approach has its merits. In DC distribution, HVDC power distribution systems permit the most resourceful employ of generated power by antithetical loss from skin effect. This allows paralleling and loads sharing amongst the generators. In AC distribution, AC Flogging is very clear-cut at high levels too. Due to its high dependence on HVDC system, a wide range of Contactors, Relays can be exploited.

While talking regarding craft Power Systems we tend to conjointly ought to contemplate increased power electronics application in craft that creates harmonics, massive neutral currents, wave form distortion of each supply voltage and current, poor power issue, and excessive current demand. Besides if some non-linear loads is affected upon a supply, their effects are additive. Due to these troubles, there could also be nuisance tripping of circuit breakers or inflated loss and thermal heating effects which will provoke early element failure. This is a prodigious problem to every motor loads on the system. Hence, decent power quality of the generation system is of scrupulous attention to the Aircraft manufacturer. We discern that aircraft systems work on high frequency so even on the higher frequencies in the range of 360 to $900 \mathrm{~Hz}$; these components would remain very significant.

Today, advanced soft computing techniques are used widely in the involuntary control system, and optimization of the system applied. Several of them are such as fuzzy logic [4]-[8], optimization of active power filter using GA [9]-[12], power loss reduction using particle swarm optimization [13], Artificial neural network control [14]-[18] applied in together machinery and filter devices. 
In this paper, Fuzzy logic controller and Adaptive Tabu search Algorithm (ATS) have been used to mend the complete performance of active filter for the lessening of harmonics and other delinquents created into the aircraft electrical system because of the non-linear loads [1]. The simulation results clearly show their effectiveness. The simulation results acquired with the new model are much improved than those of traditional method.

The paper has been modified in a sequential manner. The APF outline and the load under contemplation are discussed in Section II. The control algorithm for APF converses in Section III. MATLAB/ Simulink based simulation results are presented in Section IV, and finally Section $\mathrm{V}$ concludes the paper.

\section{System Depiction}

The craft power grid may be a three-phase power grid with the frequency of four hundred cycles per second. As exposed in Figure 1, Shunt Active Power Filter improves the power quality and compensates the harmonic currents within the system [22], [24]-[25], [27][28]. The shunt APF is understood by using one voltage supply inverters (VSIs) connected at the PCC to a typical DC link voltage [20]-23].

The set of loads for aircraft system consist of three loads. The first load is a three-phase rectifier in parallel with an inductive load and an unbalanced load connected in a phase with the midpoint (Load 1). The second one is a three phase rectifier connects a pure resistance directly (Load 2). The third one is a three-phase inductive load linked with the ground point (Load 3). Finally, a combination of all three loads connected with system together at a different time interval to study the effectiveness of the control schemes has been used to verify the functionality of the active filter in its ability to compensate for current harmonics. For the case of all three load connected, Load 1 is always connected, Load 2 is initially connected and is disconnected after every 2.5 cycles, Load 3 is connected and disconnected after every half cycle. All the simulations have been done for 15 cycles. The circuit parameters are given in Appendix.

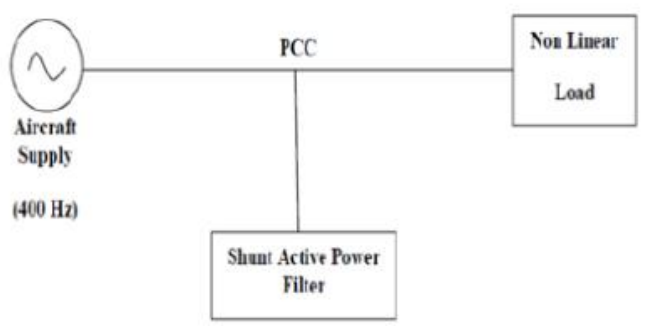

Figure 1. Aircraft system using Shunt Active Power Filter

\section{Control Theory}

The projected control of APF depends on Sinusoidal Current Control strategy, and it has been optimized for artificial intelligent techniques fuzzy logic control and Adaptive Tabu search Algorithm. Sinusoidal Current Control strategy has been mentioned in short during this section. The following section also deals with the basic application of fuzzy logic and ATS Algorithm in the control schemes [19], [20], [29].

\subsection{Sinusoidal Current Control Strategy (S.C.C.)}

The sinusoidal current control strategy could be a changed version of constant instantaneous power control strategy, which might compensate load currents underneath unbalanced states too. The modification includes a positive sequence detector that replaces the $6.4 \mathrm{KHz}$ cutoff frequency low-pass filters. It specifically matches the frequency and phase angle of the fundamental component. Thus, APF compensates the load reactive power. The extreme concern should be taken, while designing this detector, so that shunt active filter produces ac currents orthogonal to the voltage component. Otherwise, it will provide active power. $\mathrm{i}_{\alpha}, \mathrm{i}_{\beta}, \mathrm{p}^{\prime}$ and q' are attained after the calculation from $\alpha-\beta-0$ transformation block and send to the $\alpha-\beta$ 
reference voltage block, which calculates $v_{\alpha^{\prime}}$ and $v_{\beta}$. Lastly, $\alpha-\beta-0$ inverse transformation block

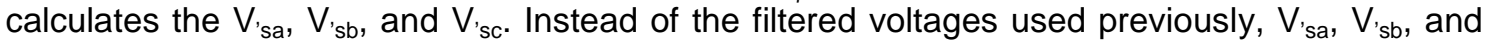
$V_{\text {sc }}$ are reflected as input to the basic control circuit of figure 2. Now fundamental negative sequence power, harmonic power, and the fundamental reactive power, are also incorporated with the compensating powers.

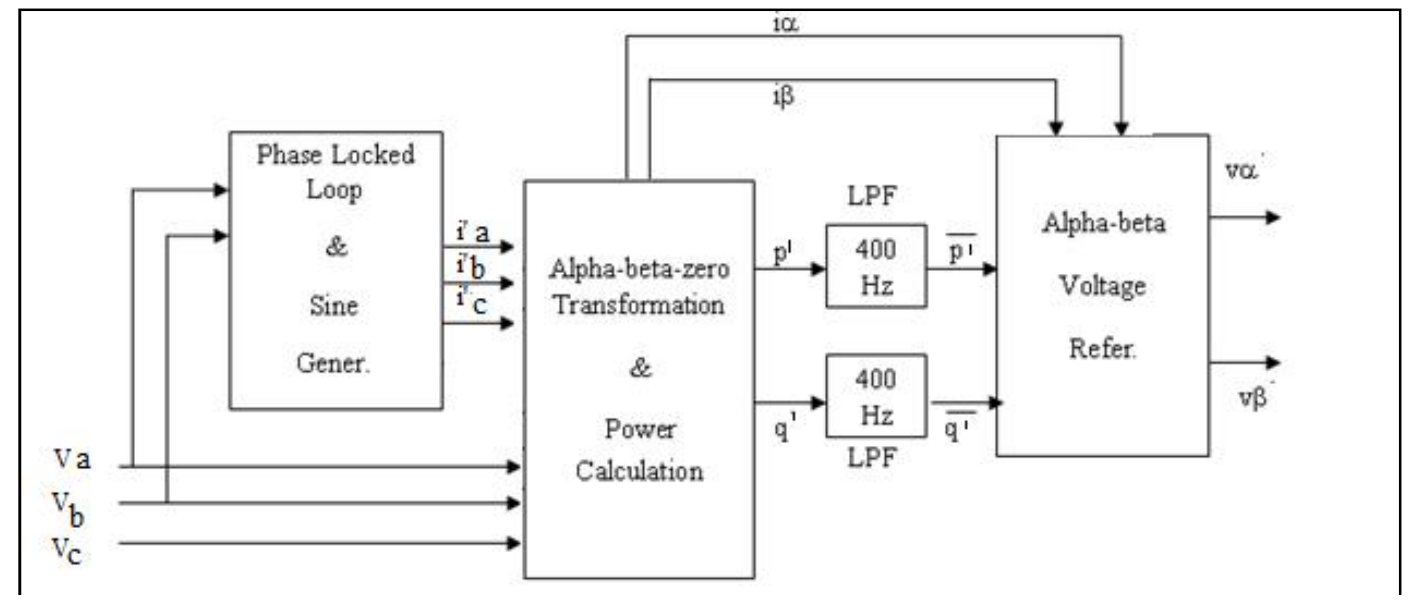

Figure 2. Block diagram of the fundamental positive-sequence voltage detector for sinusoidal current control strategy

\subsection{Fuzzy Logic Control}

In this paper, fuzzy logic control, using centrifugal defuzzification technique, is applied to the voltage control loop of the Shunt power filter. There are two inputs; error and its derivative that are used along with one command signal output, Gaussian membership functions and Triangle membership function are used as inputs and output respectively. The rules which have been used in fuzzy control are presented in Table 1. Membership functions are also shown in Figure 3.

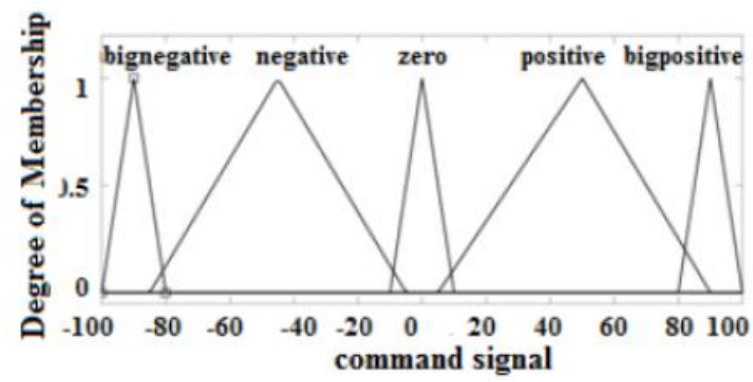

Figure 3. Membership functions

Table 1. Fuzzy Control Rule

\begin{tabular}{|c|c|c|c|}
\hline de/dt Error & Negative & Zero & Positive \\
\hline Negative & $\begin{array}{c}\text { Big } \\
\text { Negative }\end{array}$ & Positive & $\begin{array}{c}\text { Big } \\
\text { Positive }\end{array}$ \\
\hline Zero & $\begin{array}{c}\text { Big } \\
\text { Negative }\end{array}$ & Zero & $\begin{array}{c}\text { Big } \\
\text { Positive }\end{array}$ \\
\hline Positive & $\begin{array}{c}\text { Big } \\
\text { Negative }\end{array}$ & Negative & $\begin{array}{c}\text { Big } \\
\text { Positive }\end{array}$ \\
\hline
\end{tabular}




\subsection{Adaptive Tabu Search}

Glover suggested Tabu search formula for combinational optimization problem. Lateran, it has been modified and renamed as Adaptive Tabu Search (ATS). This algorithm is very efficient for solving nonlinear continuous optimization problems. The modification has been added to the new version. After modification, the novel Tabu search algorithm has discretized continuous search space, back-tracking and adaptive radius.

The novel ATS method searches the optimum value of the parameters of the proportional integral controller i.e. $\mathrm{K}_{\mathrm{p}}$ and $\mathrm{K}_{\mathrm{i}}$. The objective function gives the optimum values with the conditions of rise time, settling time and minimum overshoot. The boundary of $K_{p}$ and $\mathrm{K}_{\mathrm{i}}$, their upper limits and lower limits, then radius value, conditions for ATS backtracking, objective function and stop criteria has been defined. Maximum Searching iteration (500rounds) for ATS has been set as stop criterion. Figure 4 shows the flow chart for the search of parameters using adaptiveTabu search method.

The whole system based on three control strategies [24], [29] [31] have been simulated using MATLAB/Simulink to give the filter currents that will compensate the harmonics and make the system clean and well within standard limit [26].

\section{Simulation Results \& Discussions}

The proposed scheme of APF is simulated in MATLAB environment to estimate its performance. Three loads have been applied together at a different time interval to check the affectivity of the control schemes for the reduction of harmonics. A small quantity of inductance is additionally connected to the terminals of the load to urge the foremost effective compensation. The simulation results clearly reveal that the scheme will with success cut back the numerous quantity of THD in supply current and voltage among limits.

\subsection{Uncompensated System}

Figure 5 shows the waveforms obtained after the simulation of an uncompensated system. It has been observed that the THD of source current calculated when loads connected with the system is $9.5 \%$ and THD of source Voltage were $1.55 \%$. By observing these data, we can easily recognize supply has been polluted when loads have been connected and is obviously not within the limit of the international standard.

\subsection{Compensated System}

The performance of APF under different loads connected, when utilizing fuzzy Logic \& ATS Algorithm, have been discussed below for the control strategy given below.

\subsubsection{For Sinusoidal Current Control Strategy Using Fuzzy Logic Controller}

From Figure 6 it has been empiric that that the THDs of source current and source voltage were $2.22 \%$ and $1.01 \%$ respectively. The compensation time was $0.0066 \mathrm{sec}$. At $\mathrm{t}=0.0066 \mathrm{sec}$, it is apparent that the waveforms for source voltage and source current have become sinusoidal. Figure 6 shows the waveforms of compensation current, DC capacitor voltage, and load current.

The aberration in dc voltage can be acutely apparent in the waveforms. As per claim for accretion the compensation current for accomplishing the load current demand, it releases the energy, and after that it accuses and tries to achieve its set value. If we carefully observe, we can acquisition out that the compensation current is, in fact, accomplishing the appeal of load current, and afterward the active filtering the source current and voltage is affected to be sinusoidal.

\subsubsection{For Sinusoidal Current Control strategy using ATS Algorithm}

THDs of source current \& source voltage have been found $2.42 \%$ and $1.06 \%$ respectively after making observations from the simulation results shown in figure 7 . The waveforms for source voltage and source current have become sinusoidal at $t=0.0065 \mathrm{sec}$. Compensation time is $0.0065 \mathrm{sec}$. The waveforms of compensation current, dc capacitor Voltage, and load current have been shown in figure 7. The aberration in dc voltage can be acutely apparent in the waveforms. As per claim for accretion the compensation current for accomplishing the load current demand, it releases the energy, and after that it accuses and

IJEEI Vol. 4, No. 2, June 2016: $102-111$ 
tries to achieve its set value. If we carefully observe, we can acquisition out that the compensation current is, in fact, accomplishing the appeal of load current, and afterward the active filtering the source current and voltage is affected to be sinusoidal.

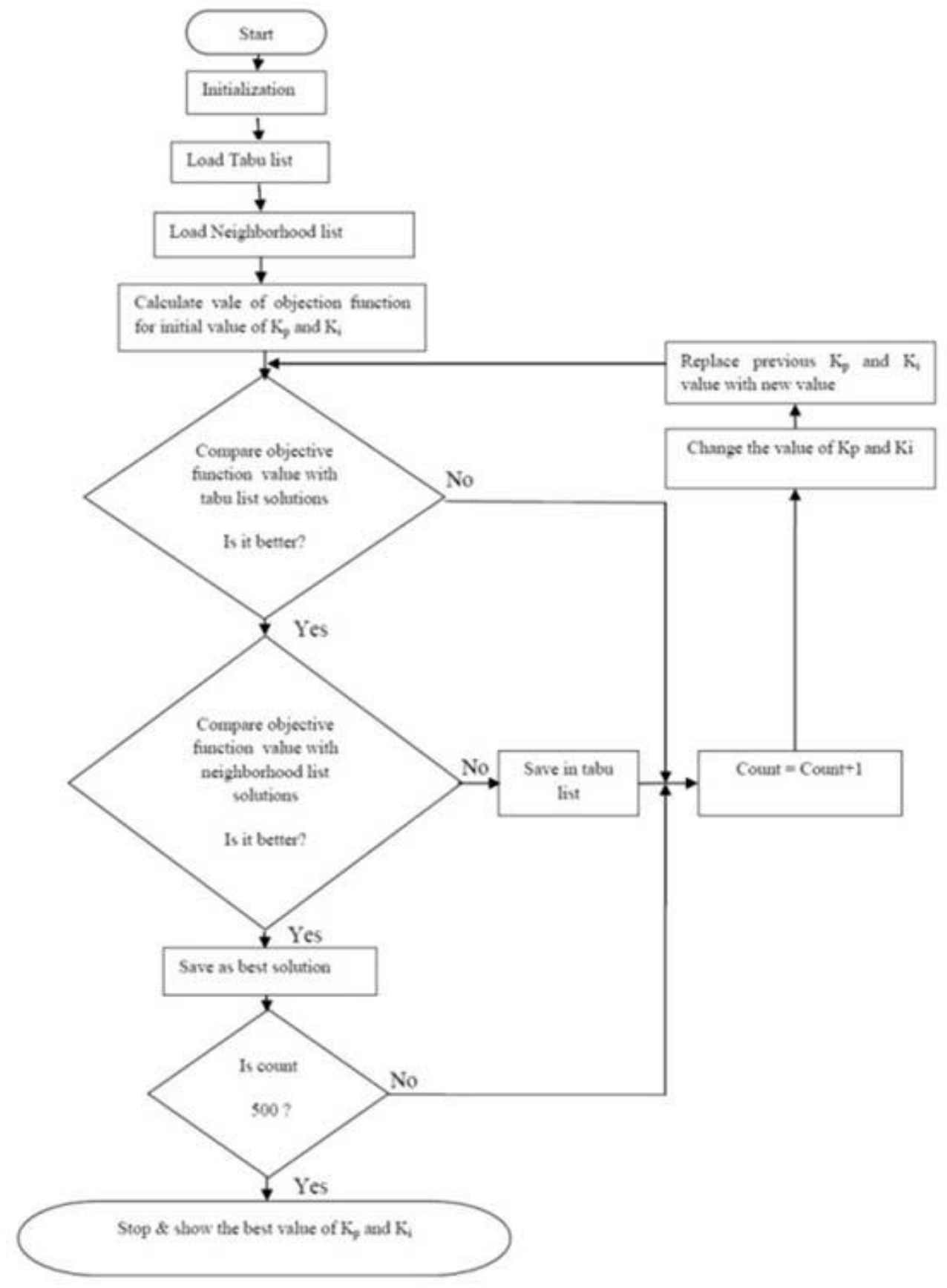

Figure 4. Flow chart for search of parameters using ATS 

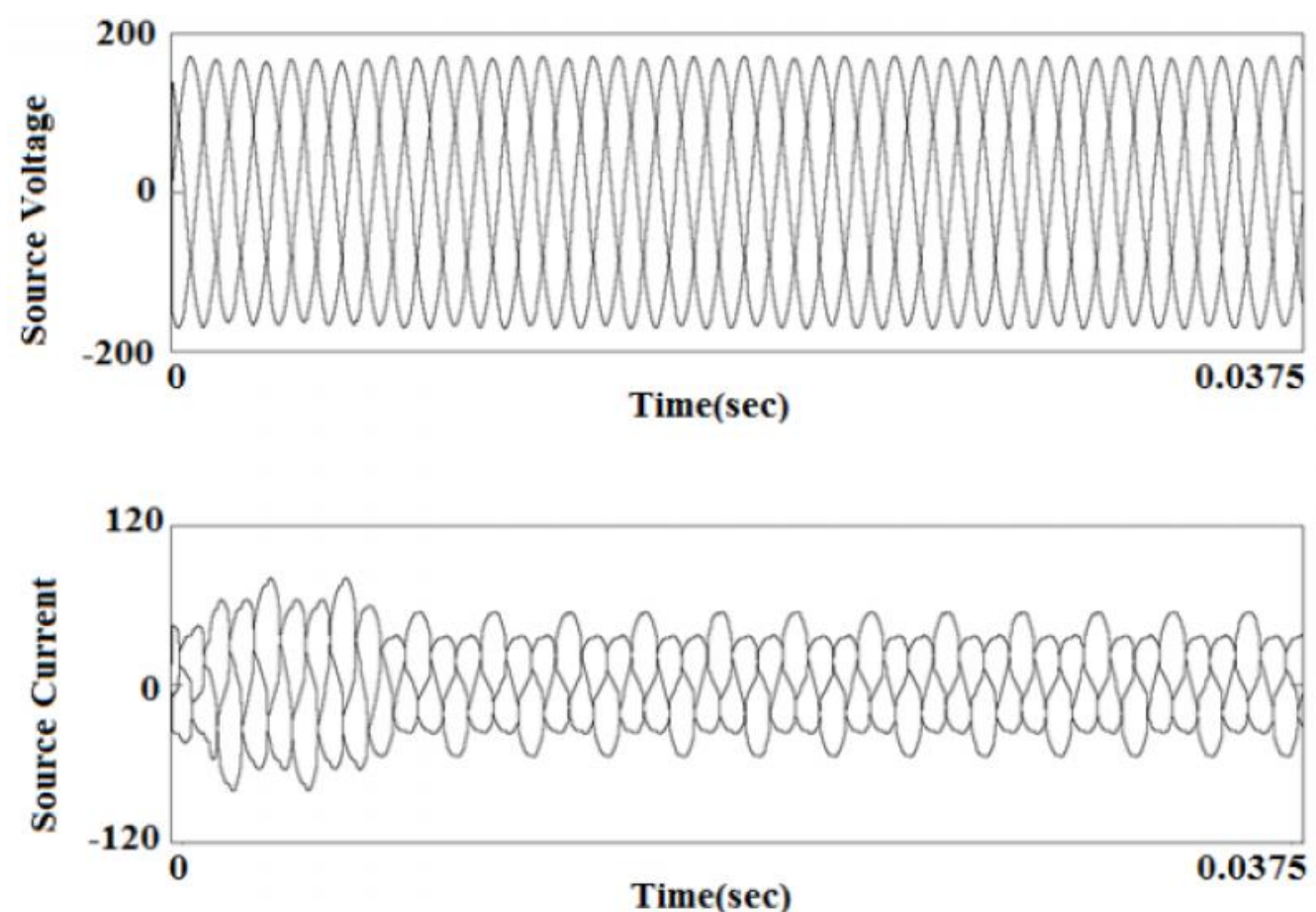

Figure 5. Source Voltage and source current waveforms of uncompensated system

\subsection{Comparative Analysis of the Simulation Results}

From the Table 2, we can easily say that Sinusoidal Current Control (SCC-Fuzzy) has been found best for current and voltage harmonic reduction. When these results have been compared based on compensation time, it has been also found that SCC-Fuzzy strategy is fastest too among all strategy. Table 3 presents a summary of the best strategy in an easy manner.

Table 2. Summary of Simulation Results Using APF for Control Strategies Using Fuzzy Logiccontroller \& ATS Algorithm

\begin{tabular}{cccc}
\hline Strategy & $\begin{array}{c}\text { THD-I } \\
(\%)\end{array}$ & $\begin{array}{c}\text { THD-V } \\
(\%)\end{array}$ & $\begin{array}{c}\text { Compensation } \\
\text { Time (sec) }\end{array}$ \\
\hline SCC-FUZZY & 2.22 & 1.01 & 0.0066 \\
SCC-ATS & 2.42 & 1.06 & 0.0065 \\
\hline
\end{tabular}

Table 3. Comparison of Strategies Used For Aircraft Power Utility

\begin{tabular}{ll}
\hline Compensation Units & Best Strategy \\
\hline THD-I(\%) & SCC-Fuzzy \\
THD-V (\%) & SCC-Fuzzy \\
Compensation Time (Sec) & SCC-ATS \\
\hline
\end{tabular}



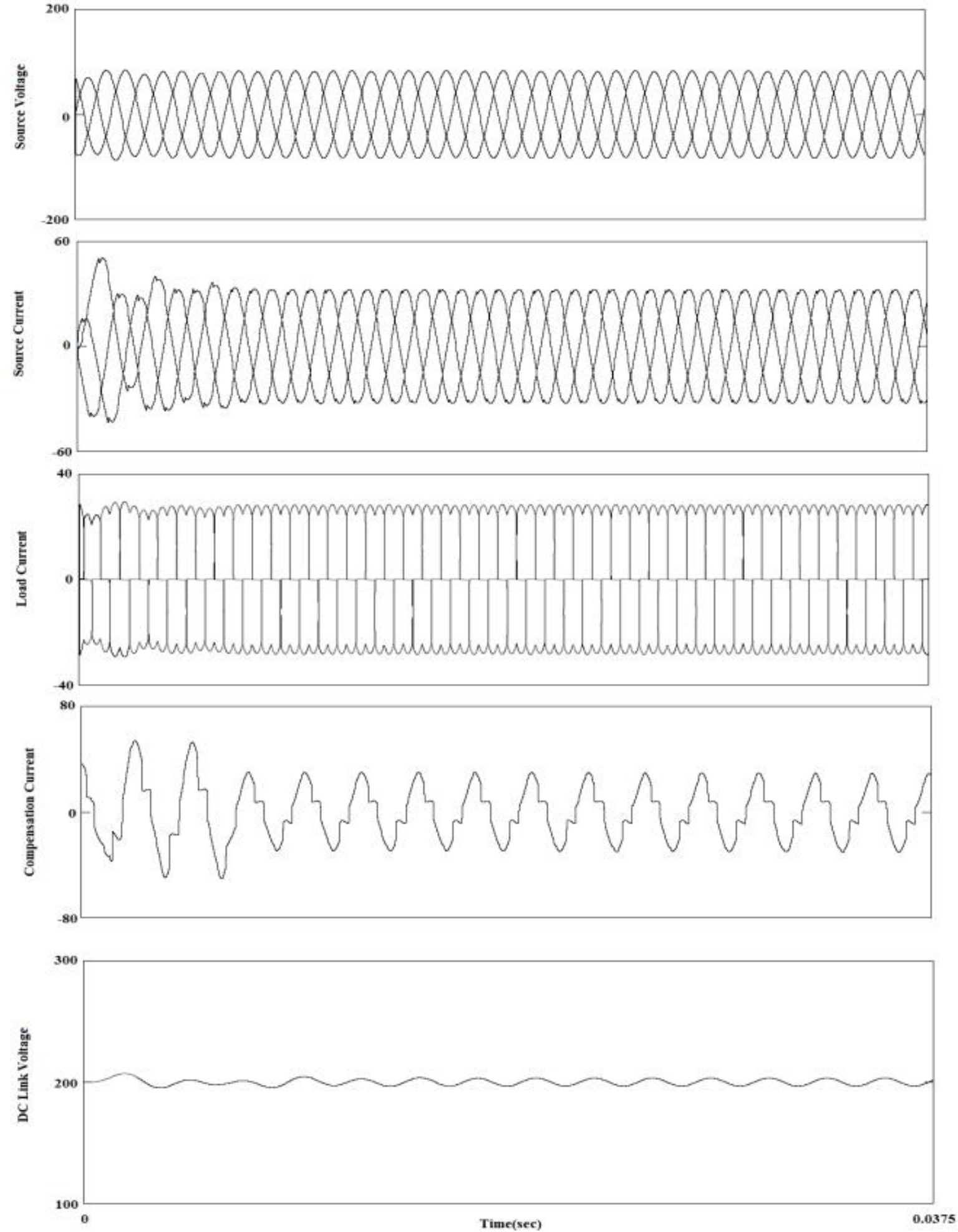

Figure 6. Source Voltage, source current, compensation current (phase b), DC link Voltage and load current waveforms of Active power filter using Sinusoidal Current Control strategy using fuzzy logic controller 

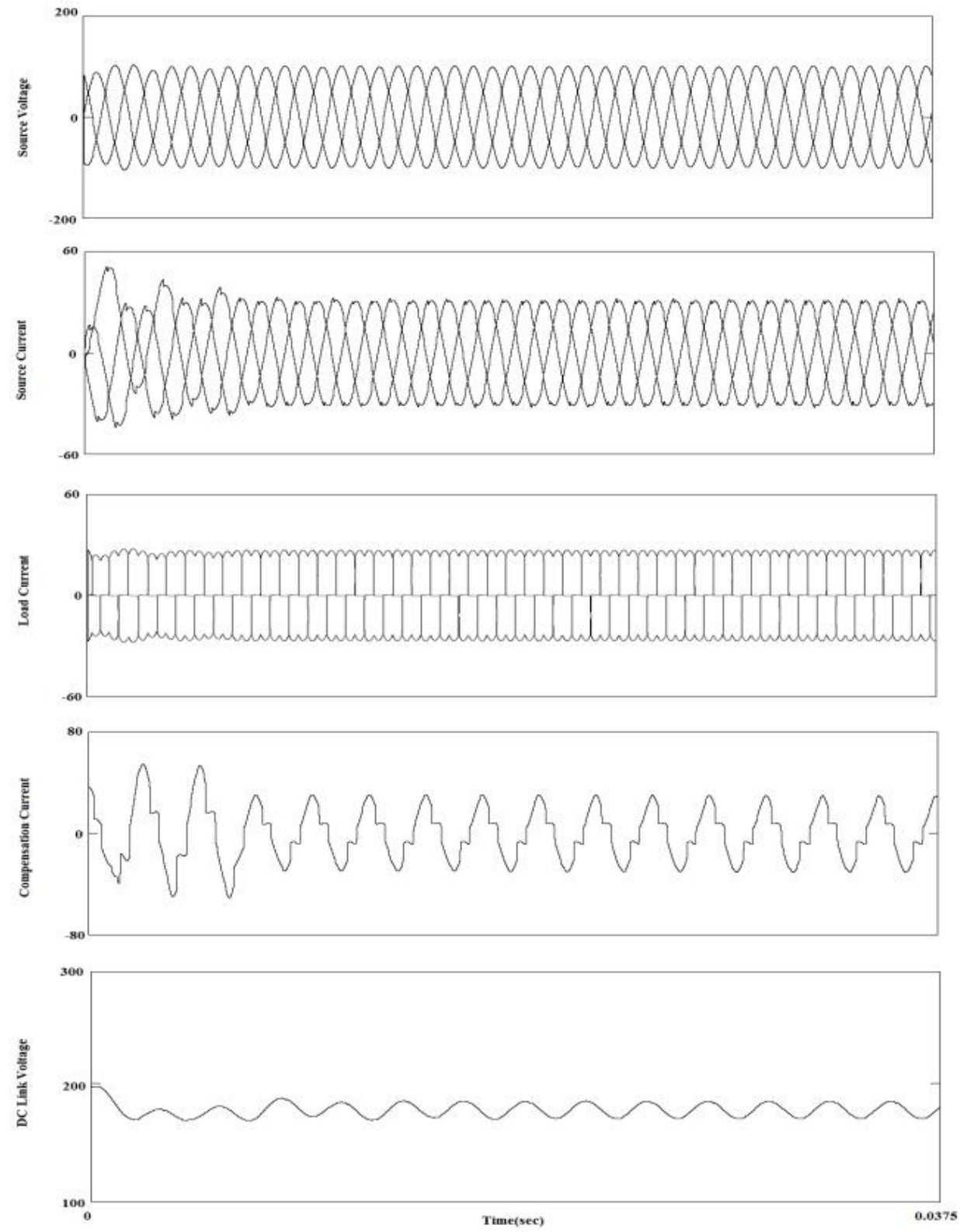

Figure 7. Source Voltage, source current, compensation current (phase b), DC link Voltage and load currentwaveforms of Active power filter using Sinusoidal Current Control strategy using ATS Algorithm

\section{Conclusion}

This paper has done an acute analysis of some traditional and soft computing control strategies for shunt APF inaircraft power utility of $400 \mathrm{HZ}$. Optimum selection of control strategy based on compensation time and THD hasbeen suggested. Overall Sinusoidal Current Control strategy (SCC-Fuzzy) has been observed as anoptimum choice. Sinusoidal Current Control Strategy's performance has been improved, which itselfan achievement for the case of optimization in traditional strategies.

\section{Appendix}

The aircraft system parameters are [1]:

Three-phase source voltage: $115 \mathrm{~V} / 400 \mathrm{~Hz}$

IJEEI Vol. 4, No. 2, June 2016 : $102-111$ 
Filter capacitor: $5 \mu \mathrm{F}$,

Filter inductor $=0.25 \mathrm{~m} \mathrm{H}$

Dc capacitor: $4700 \mu \mathrm{F}$

Dc voltage reference: $400 \mathrm{~V}$

\section{References}

[1] Chen Donghua, Tao Guo, Shaojun Xie, Bo Zhou. "Shunt Active Power Filters Applied in the Aircraft Power Utility," 36th Power Electronics Specialists Conference, PESC '05, IEEE. 2005, pp. 59-63.

[2] Khalid Saifullah, Dwivedi Bharti. Comparative Evaluation of Various Control Strategies forShunt Active Power Filters in Aircraft Power Utility of $400 \mathrm{~Hz}$. Majlesi Journal of Mechatronic Systems. 2014; 3(2): 1-5.

[3] Khalid Saifullah, Dwivedi Bharti. Application of Al techniques in implementing Shunt APF in Aircraft Supply System. Proceeding of SPRINGER- SOCROPROS Conference, IIT-Roorkee. 2013; 1: 333341.

[4] Guillermin P. Fuzzy logic Applied to Motor Control. IEEE Transactions on Industrial Application. 1996; 32(1): 51-56.

[5] Abdul Hasib A, Hew Wooi P, Hamzah A and Mowed HAF. Fuzzy Logic Control of a three phase Induction Motor using Field Oriented Control Method. Society of Instrument and Control Engineers, SICE GAual Conference. 2002: 264-267.

[6] S Jain, P Agrawal and H Gupta. "Fuzzy logic controlled shunt active power filter for power quality improvement". in IEE Proceedings of the Electric Power Applications. 2002; 149: 317-28.

[7] Mariun Norman, Bahari Samsul, Noor Mohd, Jasni Jasronita, Omar SB. A Fuzzy logic Controller for an Indirect vector Controlled Three Phase Induction Motor. Proceedings Analog and Digital Techniques in Electrical Engineering, TENCON 2004, Chiang Mai, Thailand. 2004; 4: 1-4.

[8] Afonso JL, Fonseca J, Martins JS and Couto CA. Fuzzy Logic Techniques Applied to the Control of a Three-Phase Induction Motor. Proceedings of the UK Mechatronics Forum International Conference, Portugal. 142-146.

[9] Chiewchitboon P, Tipsuwanpom P, Soonthomphisaj N and Piyarat W. Speed Control of Three-phase Induction Motor Online Tuning by Genetic Algorithm. Fifth International Conference on Power Electronics and Drive Systems, PEDS. 2003; 1: 184-188.

[10] Parmod Kumar and Alka Mahajan. "Soft Computing Techniques for the Control of an Active Power Filter". IEEE Transactions on Power Delivery. 2009; 24(1): 452-461.

[11] Bouserhane Ismail K, Hazzab Abdeldjebar, Boucheta Abdelkrim, Benyounes Mazari and Mostefa Rahli. Optimal Fuzzy Self-Tuning of PI Controller Using Genetic Algorithm for Induction Motor Speed Control. Int. J. of Automation Technology. 2008; 2(2): 85-95.

[12] Wang Guicheng, Zhang Min, Xinhe Xu and Jiang Changhong. Optimization of Controller Parameters based on the Improved Genetic Algorithms. IEEE Proceedings of the 6th World Congress on Intelligent Control and Automation, Dalian, China. 2006: 3695-3698.

[13] Thangaraj Radha, Thanga Raj Chelliah, Millie Pant, Abraham Ajit and CrinaGrosan.Optimal gain tuning of PI speed controller in induction motor drives using particle swarm optimization. Logic Journal of IGPL Advance Access. 2010: 1-14.

[14] Pinto Joao OP, Bose Bimal K and Borges da Silva Luiz Eduardo. A Stator-Flux-Oriented VectorControlled Induction Motor Drive with Space-Vector PWM and Flux-Vector Synthesis by Neural Networks. IEEE Transaction on Industry Applications. 2001; 37(5): 1308-1318.

[15] Rajasekaran S and Pai GA Vijayalakshmi. Neural Networks, Fuzzy Logic and Genetic Algorithm: Synthesis and Applications. Prentice Hall of India, New Delhi, fifth printing. 2005.

[16] Raul Rojas. Neural Network- A Systematic Introduction. Spriger-Verlag, Berlin. 1996.

[17] Zerikat $\mathrm{M}$ and Chekroun S. Adaptation Learning Speed Control for a High-Performance Induction Motor using Neural Networks. Proceedings of World Academy of Science, Engineering and Technology. 2008; 35: 294-299.

[18] Kim Seong-Hwan, Park Tae-Sik, Yoo Ji-Yoon and Park Gwi-Tae.Speed-Sensorless Vector Control of an Induction Motor Using Neural Network Speed Estimation. IEEE Transaction on Industrial Electronics. 2001; 48(3): 609-614.

[19] Khalid Saifullah, Dwivedi Bharti. Comparison of Control Strategies for Shunt Active Power Filter under balanced, unbalanced and distorted supply conditions. Proceedings of IEEE Sponsored National Conference on Advances in Electrical Power and Energy Systems (AEPES-2013). 2013: $37-$ 41.

[20] Mauricio Aredes, Jurgen Hafner, Klemens Heum GA. "Three-Phase Four-Wire Shunt Active Filter Control Strategies". IEEE Transactions on Power Electronics. 1997; 12(2): 311-318.

[21] Khalid Saifullah, Dwivedi Bharti. Power quality improvement of constant frequency aircraft electric power system using Fuzzy Logic, Genetic Algorithm and Neural network control based control scheme. International Electrical Engineering Journal (IEEJ). 2013; 4(3): 1098-1104. 
[22] Khalid Saifullah, Dwivedi Bharti. Power Quality Issues, Problems, Standards \& their Effects in Industry with Corrective Means. International Journal of Advances in Engineering \& Technology (IJAET). 2011; 1(2): 1-11.

[23] Khalid Saifullah, Dwivedi Bharti. A Review of State of Art Techniques in Active Power Filters and Reactive Power Compensation. National Journal of Technology. 2007; 1(3): 10-18.

[24] RC Dugan, MF McGranaghan and HW Beaty. Electrical Power Systems Quality. New York: McGrawHill. 1996.

[25] Khalid Saifullah, Dwivedi Bharti. Power Quality: An Important Aspect. International Journal of Engineering, Science and Technology. 2010; 2(11): 6485-6490.

[26] IEEE Recommended Practices and Requirements for Harmonic Control in Electrical Power Systems, IEEE Standard. 1992; 519-1992.

[27] A Ghosh and G Ledwich. Power Quality Enhancement Using Custom Power Devices. Boston, MA: Kluwer. 2002.

[28] S Khalid, N Vyas. Application of Power Electronics to Power System. University Science Press, INDIA. 2009.

[29] Khalid Saifullah, Dwivedi Bharti. Comparative Critical Analysis of SAF using Soft Computing and Conventional Control Techniques for High Frequency $(400 \mathrm{~Hz})$ Aircraft System. Proceeding oflEEECATCON Conference. 2013: 100-110. 